\title{
Assessment of Willingness Towards Anti-Tobacco Counseling among Adults using Tobacco - A Retrospective Study
}

Research Article

Reshma Harikrishnan ${ }^{1}$, SS Raj ${ }^{2}$, Balaji Ganesh S

${ }^{1}$ Saveetha Dental College And Hospitals, Saveetha Institute Of Medical and Technical Sciences, Saveetha University, Chennai,600050, India.

${ }^{2}$ Department of Public Health Dentistry, Saveetha Dental College and Hospitals, Saveetha Institute Of Medical And Technical Sciences, Saveetha University, Chennai, India.

${ }^{3}$ Senior Lecturer, Department of Periodontics, Saveetha Dental College and Hospitals, Saveetha Institute Of Medical And Technical Sciences, Saveetha University, Chennai, India.

\section{Abstract}

Tobacco smoking consists of drawing into the mouth and usually the lungs, smoke from burning tobacco. The popularity of tobacco smoking defies rational explanation. Despite reductions in the prevalence in recent years, it still remains one of the main preventable causes of ill health and deaths worldwide. Providing behavioural and pharmacological support can improve the rate at which those quit attempts succeed. Involvement of health professionals are also essential. They play a role in diagnosing and effectively managing tobacco dependence. Tobacco cessation has 5 major steps (5A's): Ask, Advise, Assess, Assist and Arrange. This study is to assess the patient's willingness to comply for tobacco counseling during routine treatment and their willingness to return for anti tobacco counselling review. This will aid dentists in properly encouraging patients to cease the usage of tobacco. A retrospective study was conducted in an institutional setting involving all the patients who had been diagnosed with tobacco addiction and underwent anti tobacco counselling. The time frame that was selected for data retrieval was from June 2019 to April 2020. The data was analyzed using parameters such as gender, tobacco used, willingness for counselling, second review, fagerstrom scale value. Three participants were included in this study: the researcher, reviewer and the guide. The collected data was sorted and tabulated in Excel. Its analysis was done in SPSS. The association between gender and second visit were checked. A total of 679 patients were selected for the study. 660 being male patients and the remaining 19 being female patients. $67.9 \%$ of the patients preferred smoking tobacco and the remaining $32.1 \%$ used smokeless tobacco. The willingness to undergo counselling for the cessation of tobacco use was seen in $55.8 \%$ of the patients. $0.7 \%$ of the patients were not willing. 154 of the patients re-visited the dentists to undergo a review and the second visit for the counselling. There were more male patients who had appeared for the second visit compared to female patients. Majority of the patients were willing to receive the anti tobacco counselling during the first visit but seldom returned for the second or follow-up visits showing poor compliance to quit tobacco use.

Keywords: Counselling; Harmful; Motivation; Smoking; Smokeless.

\section{Introduction}

The usage of tobacco products is one of the major and preventable causes of health issues and early deaths worldwide. Tobacco smoking consists of drawing into the mouth and usually the lungs, smoke from burning tobacco. It can also be consumed in the form of chewing, sniffing or being placed in the mouth [1].

Tobacco usage increases the chance of attaining a wide range of diseases which may be fatal. Stopping at any age is beneficial as compared to its continuation. Along with systemic diseases, there is a higher incidence of dental caries [2-7] and stains among smokers [8-14]. There are two forms of tobacco most consumed and they are: Smoking form and smokeless form [15]. Tobacco contains a biologically significant concentration of known carcinogens as well as many other toxic chemicals [16]. Nicotine sustains tobacco addiction that's a major cause of disability and premature death. It is also the substance that causes or initiates addiction [17].

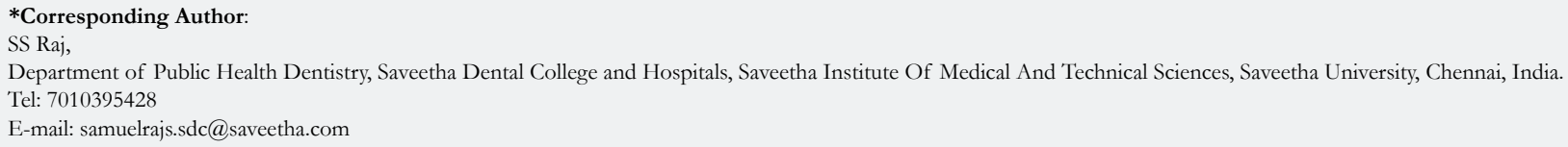

Citation: Reshma Harikrishnan, SS Raj, Balaji Ganesh S. Assessment of Willingness Towards Anti-Tobacco Counseling among Adults using Tobacco - A Retrospective Study. Int J Dentistry Oral Sci. 2019;S8:02:006:26-31. doi: http://dx.doi.org/10.19070/2377-8075-SI02-08006

Copyright: SS Raj ${ }^{\circ} 2019$. This is an open-access article distributed under the terms of the Creative Commons Attribution License, which permits unrestricted use, distribution and reproduction in any medium, provided the original author and source are credited. 
Tobacco dependence is a chronic condition that often requires repeated interventions [18]. Oral health care professionals play an important role in promoting tobacco free lifestyles $[16,19,10]$. Dentists can detect harmful effects of tobacco use which can be clinically apparent in the oral cavity at the early stages itself [1820]. They can influence children and youth to adapt a tobacco free lifestyle, by informing them regarding the dangers [12].

Tobacco cessation is essential to reduce the mortality and morbidity related to tobacco use. The methods can be classified into three: cognitive behavioural therapy, intensive therapy at smoking cessation centers and pharmacological means $[12,13,21]$. About $40 \%$ of current smokers attempt to quit each year and studies have shown that $4-6 \%$ are successful in doing so. Many professionals suggest abrupt cessation of the habit to be effective but it has been proved that a gradual reduction to be more effective. Main aspect is to maintain motivation and to make attempts [22, 23]. The national clinical guideline recommends an intervention for tobacco known as "5A's" and they are: Ask, Advise, Assess, Assist, Arrange [24].

This study aims to study the willingness of patients to undergo anti-tobacco counseling and assess patients returning for review or second visit after first anti-tobacco counselling. It will aid in proper motivation and intervention, by providing a better idea regarding the general mind set of the patients who are undergoing anti-tobacco counselling.

\section{Materials and Method}

A retrospective study was conducted in an institutional setting. The ethical clearance was received from the institute's ethical committee. (ethical approval number- SDC/ SIHEC/ 2020/ DIASDATA/ 0619-0320). The study involved all patients who had undergone anti-tobacco counselling within a given time frame of June 2019 to April 2020, in Saveetha Dental College and Hospital, Chennai.

\section{Selection of subjects}

All the patients who reported the habit of using tobacco and underwent anti-tobacco counselling were considered for the study. All age groups were taken into consideration. The time period of choice was from June 2019 to April 2020. There were three people involved in this study: the guide, reviewer and researcher. All the available data was collected and sorted. Further, the data was checked using DIAS (our patient management software) individually in case of any discrepancy.

\section{Data collection}

The detailed case sheets of each patient were reviewed and analyzed using parameters such as: gender,type of tobacco used, willingness for counselling, second review and fagerstrom scale value during primary counseling. Cross verification of the data was done by the second reviewer and when in doubt, the patient records with intra oral photographs were assessed regarding tobacco history. The data was manually retrieved and tabulated in Excel after sorting.

\section{Inclusion criteria}

Patients of all ages were considered for this study and any type of tobacco used were considered.

\section{Exclusion criteria}

Patient details that were incomplete and repeated were excluded from the study.

\section{Statistical Analysis}

The tabulated data was analysed using SPSS software (IBM SPSS statistics 26.0). The method of analysis that was used was "Chi square test". Bivariate analysis was performed and the level of statistical significance set at $5 \%$.

\section{Results and Discussion}

Gender, tobacco used, counselling and second review distribution in the study:

A total of 679 patients underwent anti-tobacco counselling as part of their first dental visit, out of which 660 patients $(97.2 \%)$ were male patients and the remaining 19 patients (2.8\%) were female patients. Male patients had a higher prevalence of tobacco use as compared to female patients who visited our dental institute. These results are shown in Figure 1.

There were two types of tobacco products used: smoking tobacco and smokeless tobacco. $67.9 \%$ of the patients used smoking tobacco and the remaining $32.1 \%$ preferred smokeless tobacco. These results are shown in Table 1 and Figure 2.

The willingness to undergo counselling for the cessation of the habit was divided into three categories: willing, somewhat willing and not willing. Majority of the patients $(55.8 \%)$ were willing and $0.7 \%$ (5 patients) were not willing to undergo counselling. The results are shown in Table 2 and Figure 3. Only a very small number of the sample did not want the counseling. Out of the 679 patients who had undergone anti tobacco counselling, only $22.7 \%$ of them (154 patients) had returned for a second review. The remaining had not retired for review counseling. This is shown in Table 3 and Figure 4.

\section{Association of gender and second review}

Out of the 660 patients who were male, 149 (21.89\%) of them had returned for a second appointment and the remaining 511 $(75.26 \%)$ did not. A total of 19 female patients who had undergone counselling and only $5(0.74 \%)$ patients came for a second review. The $\mathrm{p}$ value was $0.704(>0.05)$ and there was no significant difference statistically. These results are shown in Table 4 and Figure 5.

\section{Association of gender and type of tobacco}

Out of 660 patients who were male, 459 (67.6\%) patients preferred smoking forms of tobacco and 201 (29.6\%) preferred smokeless forms of tobacco. Within the 19 female patients, it was seen that $2(0.29 \%)$ patients preferred smoking tobacco and the 
remaining $17(2.5 \%)$ preferred smokeless forms of tobacco. The $\mathrm{p}$ value was $0.00(<0.05)$, the results were statistically significant. These results are shown in Table 5 and Figure 6.

The present study assesses the willingness of patients to undergo anti tobacco counseling and to return for second review. From the results we can see that use of tobacco was higher among men as compared to females. Tobacco in the smoking form was more preferred as compared to the smokeless. Majority of the patients were willing to receive anti tobacco counselling, but a handful returned for a second review. From the ones that had returned for the second review, most were male patients.

Tobacco usage is the leading cause of morbidity and mortality worldwide. Cessation of the habit significantly decreases the chances of diseases such as cancer, heart diseases, etc. dentists and health care workers need to consider it seriously and assist patients in its cessation. The process of cessation is prolonged and difficult [25].

The prevalence of tobacco used has been studied in various countries and the numbers differ from country to country. In the pre-

Figure 1. Gender distribution in patients with tobacco habits. Blue colour represents the number of male patients with the habit (97.2\%). Green colour represents the number of female patients with the habit in the study (2.8\%). The male to female ratio inferred that more number of male patients with tobacco consuming habits as compared to female patients.

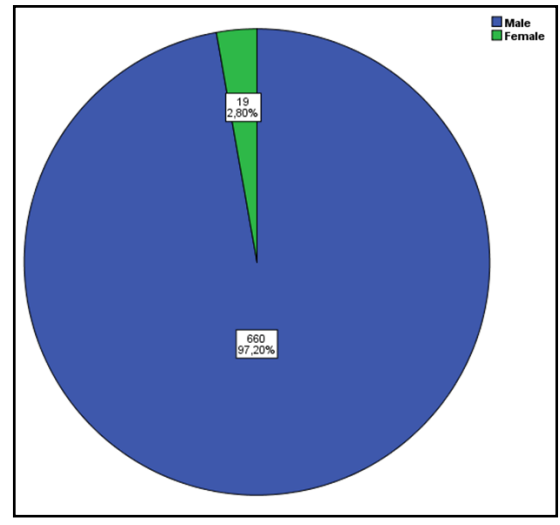

Table 1. Shows the distribution of the type of tobacco used by individuals enrolled the study.

\begin{tabular}{|c|c|c|}
\hline Type of tobacco & Frequency & Percent \\
\hline Smoking & 461 & 67.9 \\
\hline Smokeless & 218 & 3.1 \\
\hline Total & 679 & 100 \\
\hline
\end{tabular}

Table 2. Shows the number of patients who were willing for counselling in the study.

\begin{tabular}{|c|c|c|}
\hline $\begin{array}{c}\text { Willingness for } \\
\text { counselling }\end{array}$ & Frequency & Percent \\
\hline Willing & 379 & 55.8 \\
\hline Somewhat willing & 295 & 43.4 \\
\hline Not willing & 5 & 0.7 \\
\hline Total & 679 & 100 \\
\hline
\end{tabular}

Figure 2. Tobacco used distribution in the study is described. Maroon colour represents the number of patients who preferred smoking form of tobacco (67.9\%). Purple colour represents the number of patients who preferred smokeless form of tobacco $(32.1 \%)$. There were more patients who preferred the smoking form of tobacco in our study.

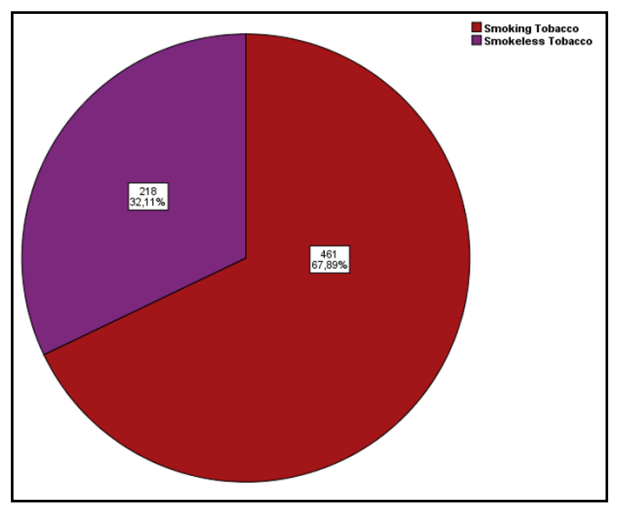


Figure 3. Number of patients who were willing for counselling in the study. Light blue colour represents the number of patients who were willing for counselling $(55.8 \%)$. Violet colour represents the number of patients who were somewhat willing for counselling (43.4\%). Beige colour represents the number of patients who were not willing to get counselling $(0.7 \%)$.

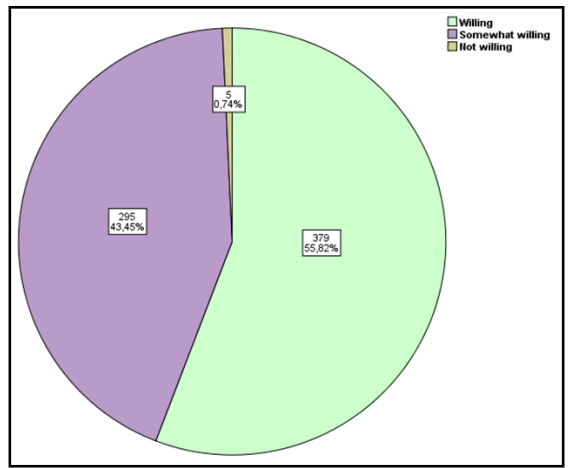

Table 3. Shows the number of patients who had returned for the second visit.

\begin{tabular}{|c|c|c|}
\hline Second visit & Frequency & Percent \\
\hline Yes & 154 & 22.7 \\
\hline No & 525 & 77.3 \\
\hline Total & 679 & 100 \\
\hline
\end{tabular}

Table 4. Chi square test: Association between Gender and Second visit. P value $>0.05$ and the association was not significant statistically.

\begin{tabular}{|c|c|c|c|}
\hline & \multicolumn{2}{|c|}{ Second Review } & \multirow{2}{*}{ Total } \\
\cline { 1 - 3 } Gender & Yes & No & \\
\hline Male & $149(21.94 \%)$ & $511(75.26 \%)$ & 660 \\
\hline Female & $5(0.74 \%)$ & $14(2.0 \%)$ & 19 \\
\hline Total & 154 & 525 & 679 \\
\hline
\end{tabular}

Figure 4. Number of patients who had returned for the second visit. Red colour represents the patients who returned for a second review (22.7\%). Orange colour represents the number of patients who did not return for the review appointment $(77.2 \%)$. Majority of the patients did not return for the second visit to counselling.

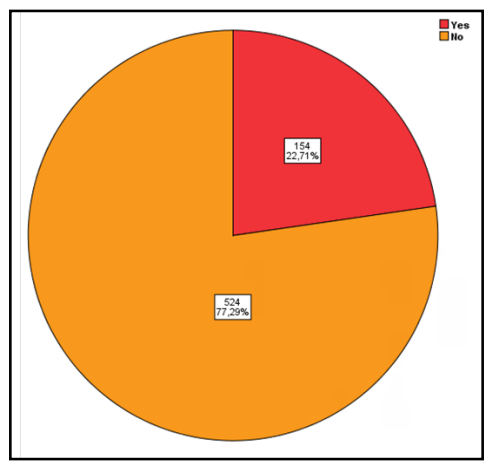

sent study, there were more male patients who were having the habit of using tobacco as compared to female patients. A comparative study by DujrudeChinwong et al., $[25,26]$ stated that developing countries have similar percentages of male and females using tobacco products and in developed countries, there was a higher prevalence among females $[25,26]$. In general, it is said that the prevalence of tobacco use is higher in males than in females, but it could differ from country to country.

Tobacco is smoked in forms of beedis and cigarettes or by using devices like hookah, chutta, etc. due to higher costs of these forms of usage, smoking is more common among the upper and middle socioeconomic classes than among poorer classes [27].
Smokeless forms of tobacco would include betel quid, gutta, pan masala, etc. these are less costly when compared to smoking tobacco and as a result have enormous use. In the present study, the majority of the patients preferred the smoking (cigarette/ beedi) type of tobacco when compared to the smokeless type. In a similar study conducted by Dina M Jones et al [28], it was stated that there were more individuals who preferred smoking tobacco instead of smokeless forms.

The willingness to quit using tobacco products should be selfinduced. Health care workers have the role of passing the information regarding the risks and also to motivate the individual. In the present study, it was seen that the majority of the patients 
Figure 5. Bar chart shows the association between Gender and Second visit. X-axis represents the gender of the patients (Male and Female). Y-axis represents the number of patients involved in each category. Red colour bars represent "Yes" and Orange colour represents "No"; for the patients who had and had not returned for the second visit of counselling.

There was a significantly higher number of patients who were males as compared to females. Majority of the patients who had undergone the 1 st counselling did not return for the second visit, however this is statistically not significant. ( $P$ value 0.704 (>0.05 - not significant)).

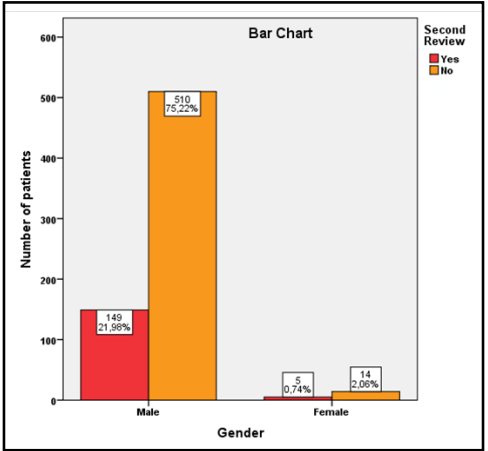

Table 5. Chi square test: Association between Gender and Type of tobacco used. $P$ value $<0.05$ and the association was not significant statistically.

\begin{tabular}{|c|c|c|c|}
\hline & \multicolumn{2}{|c|}{ Type of tobacco } & \multirow{2}{*}{ Total } \\
\cline { 1 - 3 } Gender & Smoking & Smokeless & \\
\hline Male & $\begin{array}{c}459 \\
(67.6 \%)\end{array}$ & $\begin{array}{c}201 \\
(29.6 \%)\end{array}$ & 660 \\
\hline Female & $2(0.29 \%)$ & $17(2.5 \%)$ & 19 \\
\hline Total & 461 & 218 & 679 \\
\hline
\end{tabular}

Figure 6. Bar chart represents the association between gender and the type of tobacco used. X-axis represents the gender (Male and Female). Y-axis represents the patients involved in each category. Maroon colour represents the number of patients who preferred smoking form of tobacco. Purple colour represents the number of patients who prefer smokeless forms of tobacco. There was a significantly higher number of male patients who preferred smoking form of tobacco in comparison to smokeless form. Within female patients, it was seen that the majority of the patients preferred the smokeless form of tobacco and this difference was statistically significant ( $p$ value $-<0.001$ ).

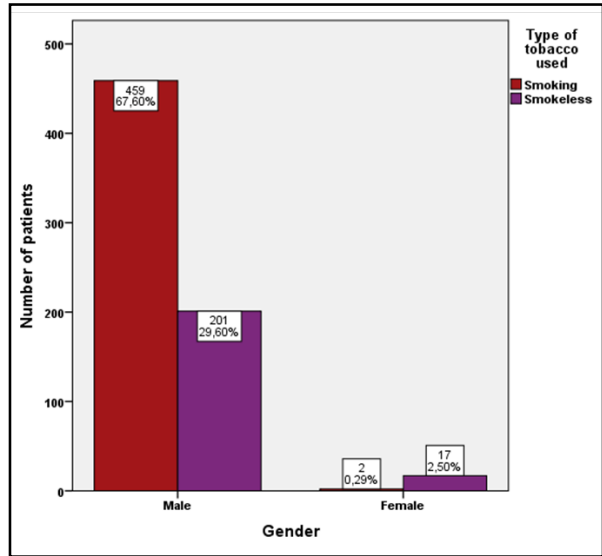

were willing to receive the counselling from the dentists. Receiving counselling is one of the first steps in cessation of the habit. In a similar study conducted by Mahendra $\mathrm{M}$ et al [29], it was seen that $50.9 \%$ of the patients were ready to quit the habit. This was mostly seen in patients who were young and also those who had knowledge regarding the adverse effects.

In the present study, it was seen that the majority of the patients had not turned up for the second session of counselling. This could be due to the lack of motivation or proper counselling given. It could also be due to disinterest from the individuals side. A study done in 2013 by Radhakrishnan et al [30] stated that out of
928 patients that were involved in the study, 232 of them did not attempt to cease the habit nor turn up for review.

Appearing for the second review visit to the health care practitioner would state that the patient is willing to quit the habit of consuming tobacco. In the present study, more number of ale patients returned for counselling than female patients. This could be due to most female patients who use tobacco products in the area were older women who used smokeless forms. In the study by DhujdeeChinwong et al [31], it was seen that female individuals were more keen and interested in quitting the habit than male patients. 


\section{Study limitations}

This study focused on a small area in South India and so it cannot be generalized to the entire population. The sample size was relatively smaller with an unequal number of male and female patients. Moreover, this is an institutional sample and anti tobacco counseling is provided irrespective of the individual's choice and we might overestimate the actual willingness towards anti tobacco counseling.

\section{Future scope}

In future studies, a larger population can be taken into consideration to have better results.

\section{Conclusion}

Within the limits of the study, it was seen that male patients were keen on using tobacco products than female patients. The more commonly used form of tobacco was in smoking form. Majority of the individuals were willing to receive counselling during the first visit but very few returned for the second visit.

\section{Acknowledgement}

The authors are thankful to Saveetha Dental College for providing a platform to express our knowledge.

\section{References}

[1]. Vinod VC, Taneja L, Mehta P, Koduri S. Dental professionals as a counsellor for tobacco cessation: A survey. J Indian Acad Oral Med Radiol. 2017 Jul 1;29(3):209.

[2]. Samuel SR, Acharya S, Rao JC. School Interventions-based Prevention of Early-Childhood Caries among 3-5-year-old children from very low socioeconomic status: Two-year randomized trial. J Public Health Dent. 2020 Jan;80(1):51-60.Pubmed PMID: 31710096.

[3]. Khatri SG, Madan KA, Srinivasan SR, Acharya S. Retention of moisturetolerant fluoride-releasing sealant and amorphous calcium phosphate-containing sealant in 6-9-year-old children: A randomized controlled trial. J Indian SocPedodPrev Dent. 2019 Jan-Mar;37(1):92-98.Pubmed PMID: 30804314

[4]. Mathew MG, Samuel SR, Soni AJ, Roopa KB. Evaluation of adhesion of Streptococcus mutans, plaque accumulation on zirconia and stainless steel crowns, and surrounding gingival inflammation in primary molars: randomized controlled trial. Clin Oral Investig. 2020 Sep;24(9):3275-3280.Pubmed PMID: 31955271.

[5]. Parker DR. A dental hygienist's role in tobacco cessation. International Journal of Dental Hygiene. 2003 May; 1(2):105-9.

[6]. Prabakar J, John J, Arumugham IM, Kumar RP, Sakthi DS. Comparing the Effectiveness of Probiotic, Green Tea, and Chlorhexidine- and Fluoride-containing Dentifrices on Oral Microbial Flora: A Double-blind, Randomized Clinical Trial. ContempClin Dent. 2018 Oct-Dec;9(4):560-569.Pubmed PMID: 31772463

[7]. Mohapatra S, Kumar RP, Arumugham IM, Sakthi D, Jayashri P. Assessment of Microhardness of Enamel Carious Like Lesions After Treatment with Nova Min, Bio Min and Remin Pro Containing Toothpastes: An in Vitro Study. Indian J Public Health Res Dev. 2019;10(10):375-80.

[8]. Prabakar J, John J, Srisakthi D. Prevalence of dental caries and treatment needs among school going children of Chandigarh. Indian J Dent Res. 2016 Sep-Oct;27(5):547-552.Pubmed PMID: 27966516.

[9]. Prabhakar AR, Murthy SA, Sugandhan S. Comparative evaluation of the length of resin tags, viscosity and microleakage of pit and fissure sealants an in vitro scanning electron microscope study. ContempClin Dent. 2011 Oct;2(4):324-30.Pubmed PMID: 22346161.

[10]. Kumar RP, Vijayalakshmi B. Assessment of fluoride concentration in ground water in Madurai district, Tamil Nadu, India. Res J Pharm Technol. 2017;10(1):309-10.

[11]. Kumar RP, Preethi R. Assessment of Water Quality and Pollution of Porur, Chembarambakkam and Puzhal Lake. Res J Pharm Technol. 2017;10(7):2157-9.

[12]. Pratha AA, Prabakar J. Comparing the effect of Carbonated and energy drinks on salivary pH-In Vivo Randomized Controlled Trial. Res J Pharm Technol. 2019;12(10):4699-702.

[13]. Harini G, Leelavathi L. Nicotine replacement therapy for smoking cessationAn overview. Indian J Public Health Res Dev. 2019;10(11):3588.

[14]. Prabakar J, John J, Arumugham IM, Kumar RP, Srisakthi D. Comparative Evaluation of Retention, Cariostatic Effect and Discoloration of Conventional and Hydrophilic Sealants - A Single Blinded Randomized Split Mouth Clinical Trial. ContempClin Dent. 2018 Sep;9(Suppl 2):S233-S239.Pubmed PMID: 30294150

[15]. West R. Tobacco smoking: Health impact, prevalence, correlates and interventions. Psychol Health. 2017 Aug 3;32(8):1018-36.

[16]. Pavithra RP, Jayashri P. Influence of Naturally Occurring Phytochemicals on Oral Health. Res J Pharm Technol. 2019;12(8):3979-83.

[17]. Pavithra RP, Jayashri P. Influence of Naturally Occurring Phytochemicals on Oral Health. Res J Pharm Technol. 2019;12(8):3979-83.

[18]. Shrivastava SR, Shrivastava PS, Ramasamy J. Implementing mTobacco Cessation program in India to assist users in quitting tobacco: World Health Organization. Ann Trop Med Public Health. 2017 Nov 1;10(6):1417.

[19]. KANNAN SS, KUMAR VS, RATHINAVELU PK, INDIRAN MA. AWARENESS AND ATTITUDE TOWARDS MASS DISASTER AND ITS MANAGEMENT AMONG HOUSE SURGEONS IN A DENTAL COLLEGE AND HOSPITAL IN CHENNAI, INDIA. WIT Transactions on The Built Environment. 2017 Sep 7;173:121-9.

[20]. Tomar SL. Dentistry's role in tobacco control. J Am Dent Assoc. 2001 Nov $1 ; 132: 30 S-5 S$

[21]. Shaik SS, Doshi D, Bandari SR, Madupu PR, KuLKARNI S. Tobacco use cessation and prevention-A review. J ClinDiagn Res. 2016 May;10(5):ZE13.

[22]. Hughes JR. Motivating and helping smokers to stop smoking. J Gen Intern Med. 2003 Dec 1;18(12):1053-7.

[23]. Neralla M, Jayabalan J, George R, Rajan J, MP SK, Haque AE, et al. Role of nutrition in rehabilitation of patients following surgery for oral squamous cell carcinoma. Int. J. Res. Pharm. Sci. 2019 Oct 16;10(4):3197-203.

[24]. Quinn VP, Hollis JF, Smith KS, Rigotti NA, Solberg LI, Hu W, et al. Effectiveness of the 5-As tobacco cessation treatments in nine HMOs. J Gen Intern Med. 2009 Feb;24(2):149-54.Pubmed PMID: 19083066.

[25]. Patel A, Patel A, Patel B. Methods of smoking cessation. The Journal of National Accreditation Board for Hospitals \& Healthcare Providers 2016; 3: 1.

[26]. Chinwong D, Mookmanee N, Chongpornchai J, Chinwong S. A Comparison of Gender Differences in Smoking Behaviors, Intention to Quit, and Nicotine Dependence among Thai University Students. J Addict. 2018 Oct 24;2018:1-8.Pubmed PMID: 30473903.

[27]. Chadda RK, Sengupta SN. Tobacco use by Indian adolescents. Tob Induc Dis. 2002 Jun 1;1(2):111-119.

[28]. Jones DM, Popova L, Weaver SR, Pechacek TF, Eriksen MP. A national comparison of dual users of smokeless tobacco and cigarettes and exclusive cigarette smokers, 2015-2016. Nicotine Tob. Res. 2018 Aug 14;20(suppl_1):S62-70.

[29]. Reddy MM, Kanungo S, Naik BN, Kar SS. Willingness to quit tobacco smoking and its correlates among Indian smokers-Findings from Global Adult Tobacco Survey India, 2009-2010. Journal of Family Medicine and Primary Care. 2018 Nov;7(6):1353.

[30]. Jayakrishnan R, Uutela A, Mathew A, Auvinen A, Mathew PS, Sebastian P. Smoking cessation intervention in rural kerala, India: findings of a randomised controlled trial. Asian Pac J Cancer Prev. 2013;14(11):6797-802. Pubmed PMID: 24377608.

[31]. Chinwong S, Chinwong D. Roles of community pharmacists in providing smoking cessation services: a national survey in Thailand. InTOBACCO INDUCED DISEASES 2018 Jan 1 (Vol. 16, pp. 197-197). SCIENCE \& TECHNOLGY PARK CRETE,(STEP-C), N PLASTIRA 100, VASSILIKA VOUTWN, HERAKLION, CRETE 00000, GREECE: EUROPEAN PUBLISHING. 